\title{
FOTOGRAFÍA Y ARQUITECTURA PÚBLICA EN ARGENTINA. UN SIGLO EN IMÁGENES
}

\author{
Susana Castillo
}

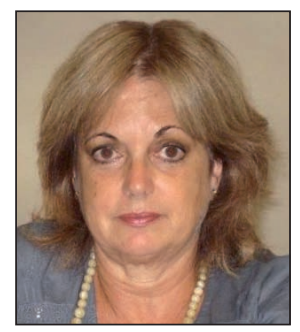

Susana Castillo, arquitecta egresada de la Universidad de Buenos Aires, es coordinadora del Centro de Documentación e Investigación de la Arquitectura Pública (CeDIAP) que forma parte del Centro de Documentación e Información del Ministerio de Economía y Finanzas Públicas de Argentina. Trabaja en proyectos y publicaciones relacionadas con la gestión de la información y la difusión del patrimonio cultural.

Centro de Documentación e Investigación de la Arquitectura Pública Centro de Documentación e Información Ministerio de Economía y Finanzas Públicas

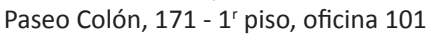
Buenos Aires, Argentina scasti@mecon.gob.ar http://cdi.mecon.gov.ar/cediap

\section{Resumen}

El Centro de Documentación e Información (CDI) del Ministerio de Economía y Finanzas Públicas (Argentina) se especializa en la gestión de productos y servicios de información sobre temas económicos, técnicos, legales y relativos al patrimonio arquitectónico oficial. Sus actividades contribuyen con la construcción de conocimientos locales, en un entorno de acceso cada vez más global. Estas actividades incluyen la ejecución de proyectos que, desarrollados transversalmente por áreas especializadas, responden a las demandas de los usuarios o las anticipan con productos que agregan valor a las colecciones. Presentamos la experiencia en el tratamiento de la colección de planos y fotografías sobre construcción de edificios públicos. Albergada en el Centro de Documentación e Investigación de la Arquitectura Pública (CeDIAP), esta colección sirvió de materia prima para un trabajo sobre la historia edilicia del Palacio de Hacienda desarrollado en el marco de un proyecto de memoria institucional.

\section{Palabras clave}

Memoria institucional, Acceso a la información, Fotografías históricas, Patrimonio cultural, Arquitectura pública, Digitalización, Bases de datos, Gestión del conocimiento, Diseño de proyectos, Procesamiento de la información.

\section{Title: Photography and public architecture in Argentina. A century in images}

\begin{abstract}
The Documentation and Information Center $(C D I)$ of the Ministry of Economy and Public Finance (Argentina) develops information products and services related to economic, technical and legal issues, and the official architectonic heritage. The activities undertaken contribute to the creation of local knowledge, in a context of increasing global access. These activities involve integrated project design and implementation, and respond to or anticipate users' demands with products that add value to collections. Here we showcase our experience in the treatment of blueprints and photographs referring to the construction of public buildings. Collected by the Center for Documentation and Research on Public Architecture (CeDIAP), these were used as raw materials to work on a specific task related to the construction and dissemination of the building's history, within the framework of a wider project which undertakes the construction and dissemination of the ministry's institutional memory.
\end{abstract}

\section{Keywords}

Institutional history, Information access, Historical photographs, Cultural heritage, Public architecture, Digitization, Databases, Knowledge management, Project design, Information processing.

Castillo, Susana. "Fotografía y arquitectura pública en Argentina. Un siglo en imágenes". El profesional de la informacion, 2011, v. 20, n. 4, pp. 448-455. 


\section{Introducción}

A comienzos de 1990 se estableció el Centro de Documentación e Información (CDI) para coordinar el acervo documental de distintas unidades de información gubernamental que dependían del entonces Ministerio de Economía y Obras y Servicios Públicos. Conformado por la Biblioteca Económica, las Bibliotecas Técnicas de Obras Públicas y Transporte e Infoleg (información legislativa), integró en 2000 al CeDIAP que había sido creado en 1993 para gestionar el archivo técnico de arquitectura. Así, en el entramado de referencias a otras colecciones, planos y fotografías adquieren plena significación.

La transformación del archivo técnico en un centro de documentación e investigación se profundiza sustentado en el trabajo cooperativo y alianzas con otros centros especializados y, además, contribuye a la transferencia de buenas prácticas y a la preservación del patrimonio tanto por el tratamiento aplicado a los originales como por la gestión de información, la difusión del acervo documental y la elaboración de productos destinados a sensibilizar al ciudadano.

\section{Producción documental para arquitectura pública}

Los 300.000 planos y 100.000 fotografías preservados por el CeDIAP, fueron producidos por el que fuera Ministerio de Obras Públicas de la Nación para documentar la construc-

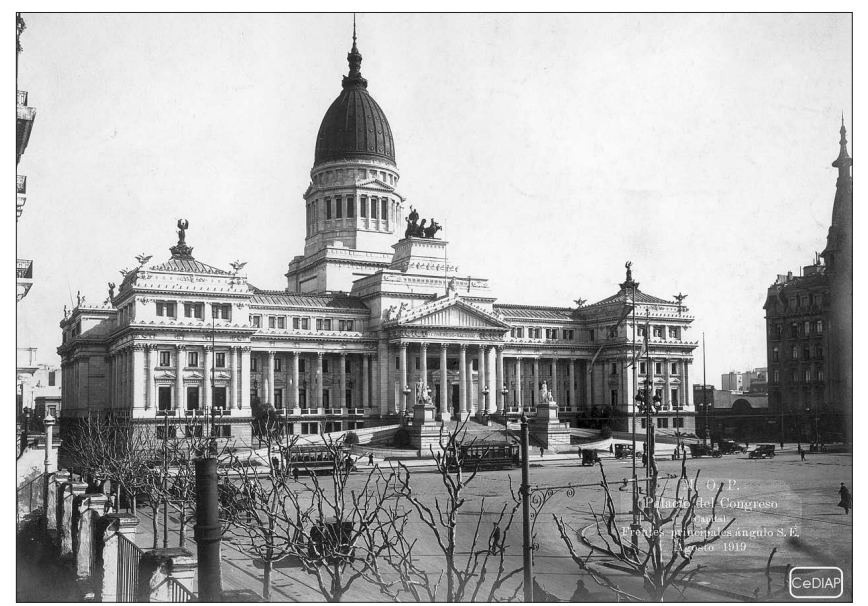

Congreso Nacional en Ciudad de Bs. As. Fotografía nº5511.

Titulo: frente principal. 01-08-1919. MOP

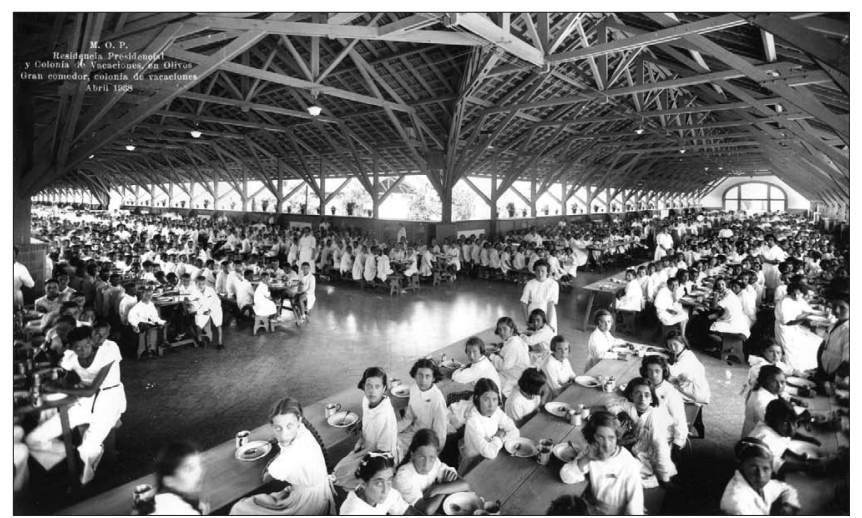

Residencia Presidencial y Colonia de Vacaciones -Edificio existente-en Olivos. Fotografía $n^{\circ}$ 19600. Gran comedor, colonia de vacaciones. 01-04-1938. MOP ción de 8.500 obras de arquitectura pública e infraestructura ejecutadas en el país desde 1880 a lo largo de un siglo.

Estos edificios públicos se conectan con planes y políticas de construcción de escuelas, hospitales, hospicios, viviendas sociales y penitenciarías dentro de programas y políticas nacionales.

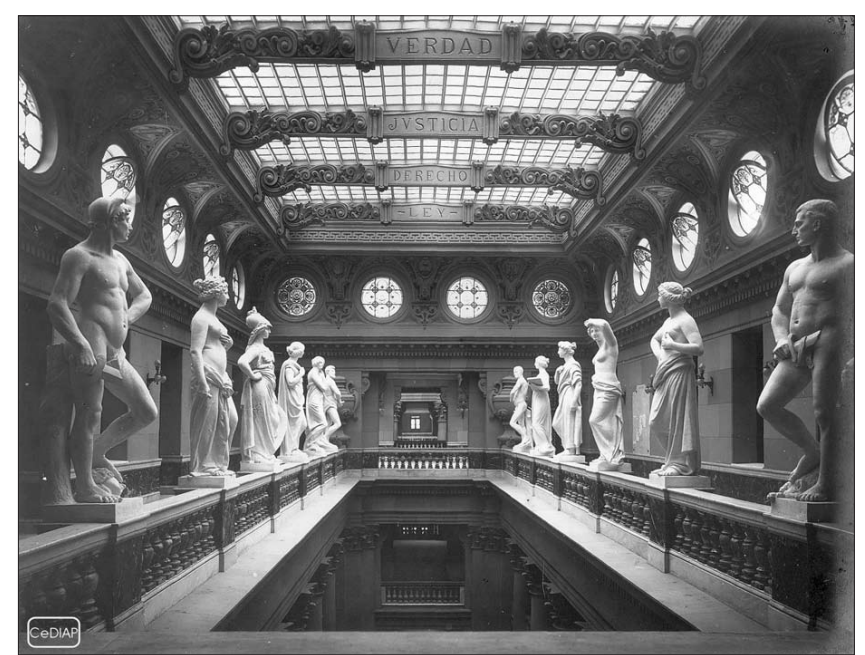

Palacio de Justicia en Ciudad de Bs. As. Fotografía ${ }^{\circ}$ 00246. Galería estatuas. MOP

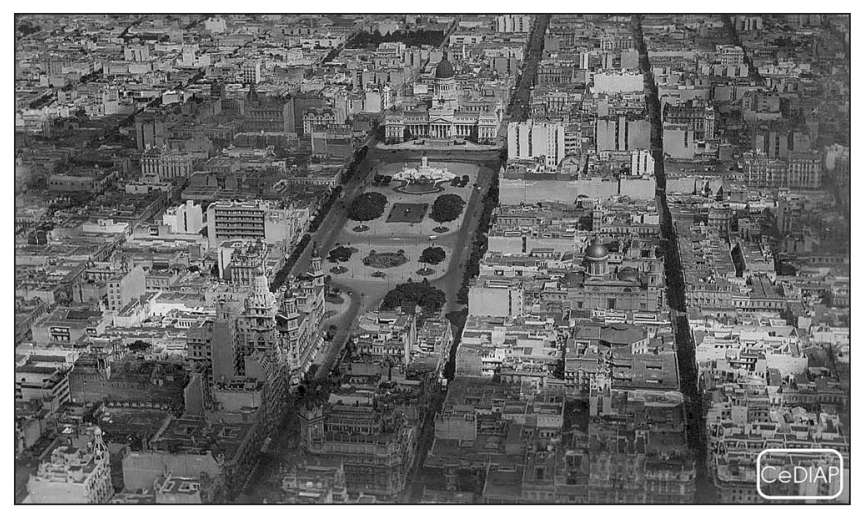

Congreso Nacional en Ciudad de Bs. As.

Fotografía $n^{\circ}$ al041pa078 b. Vista general aérea. S/f. MOP

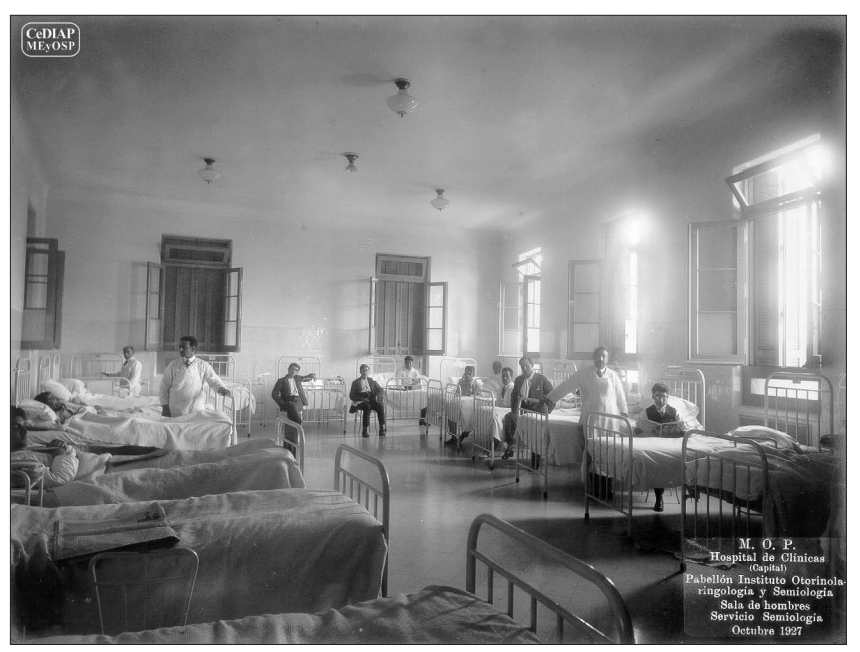

Facultad de Ciencias Económicas y Morgue Judicial ex Facultad de Medicina en Ciudad de Bs. As.

Fotografía $n^{\circ}$ 12017. Pabellón Instituto Otorrinolaringología y Semiología. Sala de hombres. Servicio Semiología. 01-10-1927. MOP 


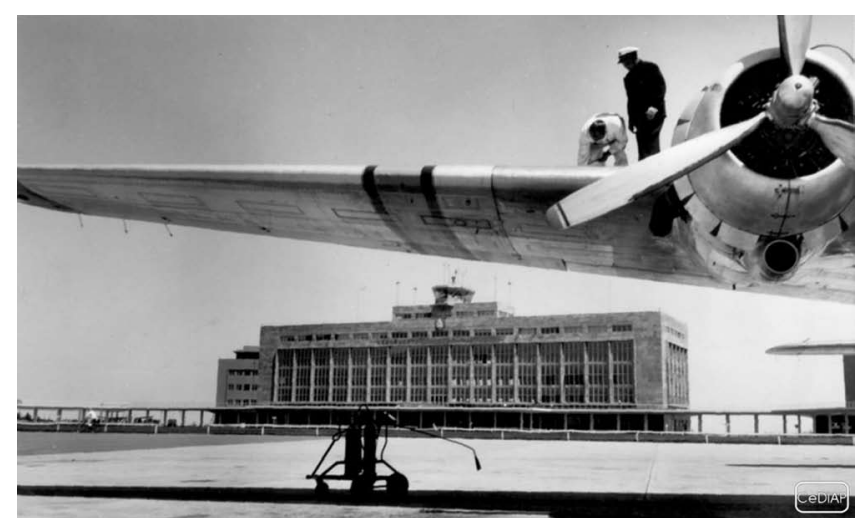

Aeropuerto y barrio Esteban Echeverría en Ezeiza.

Fotografía n 05914. Detalle ala de avión. Aeroestación al fondo. S/f. MOP

Algunos de ellos mantienen el uso para el que fueron concebidos; otros sufrieron modificaciones y refuncionalizaciones; de otros, ya demolidos, sólo dan testimonio los documentos, planos y fotografías. Este acervo documental conservado y procesado digitalmente, constituye una herramienta valiosa para el conocimiento de la historia edilicia, su mantenimiento o intervención, su protección y puesta en valor.

El contenido de los planos es netamente técnico, aun cuando muchos de ellos constituyen magníficas obras de arte escondidas en minuciosos y artesanales dibujos. Cada serie de fotografías se refiere a la construcción de un edificio y en ellas, la mirada actual descubre sugerentes registros que revelan el contexto físico y el entorno urbano y social en que fue realizado. Suele comenzar con imágenes del predio destinado a la obra (incluso de la demolición de edificios preexistentes), muestra etapas, procesos, técnicas y sistemas constructivos, máquinas y herramientas, problemas o fallas hasta llegar al registro del edificio terminado. Parques y jardines, exteriores, interiores, luminarias, mobiliario, detalles, protagonistas (operarios y directores de obra) y usuarios (alumnos de escuela o pacientes internados en hospitales): ninguno escapa a la fotografía. Y en aquellas obras de impacto urbanístico, no faltan las tomas desde un "aeroplano".

\section{Sugerentes registros fotográficos revelan los aspectos técnicos de la construcción edilicia y los detalles testimoniales del entorno urbano y social}

La información técnico-gráfica se complementa con las Memorias y Boletines de Obras Públicas de las Bibliotecas Técnicas y aporta un valioso marco de referencia para el conocimiento y puesta en valor de los edificios públicos

\section{Los documentos fotográficos}

La aplicación de procesos para el tratamiento y preservación de los documentos fotográficos originales, así como las políticas vinculadas con la gestión de la información, se decidieron luego de evaluar diversos aspectos físicos y de contenido, entre otros:

- Tipos de documentos. Copias papel y negativos en diversos formatos, soportes y técnicas, como papel a la albú-

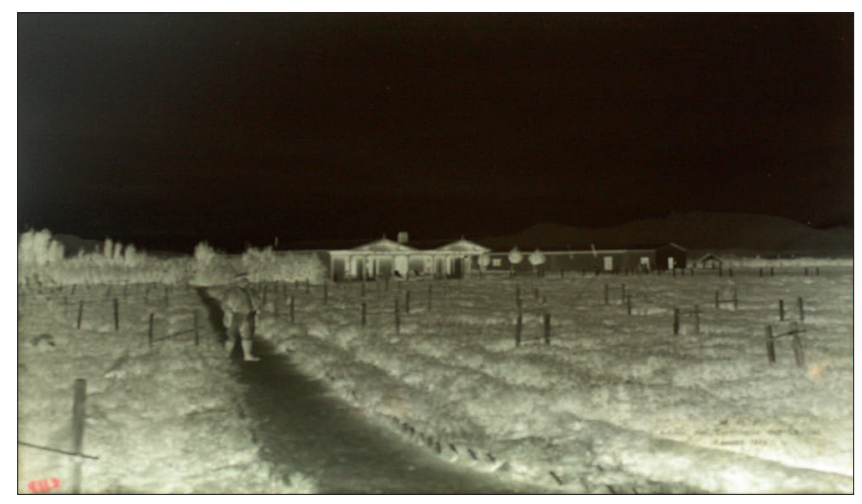

Soportes. Toma fotográfica de un negativo de gelatina sobre vidrio $18 \times 24$ $\mathrm{cm}$ en una mesa transiluminada. CeDIAP.
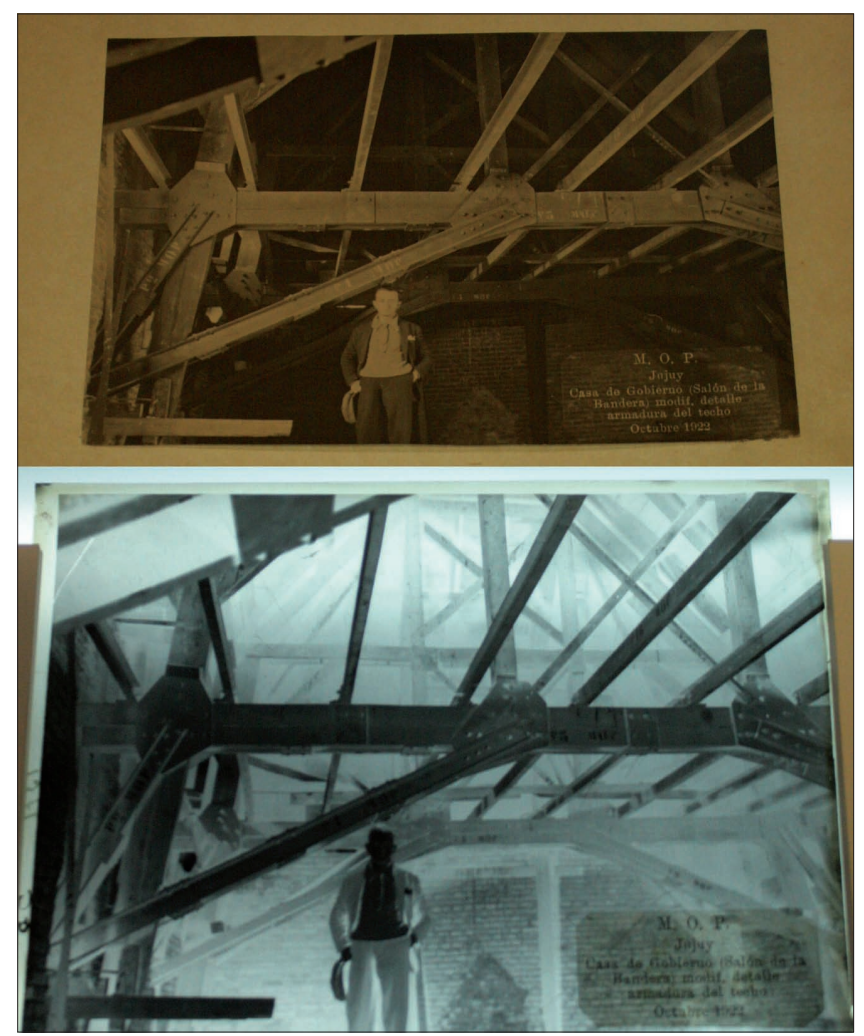

Soportes. Toma fotográfica de un nitrato con su copia en mesa transiluminada. CeDIAP.

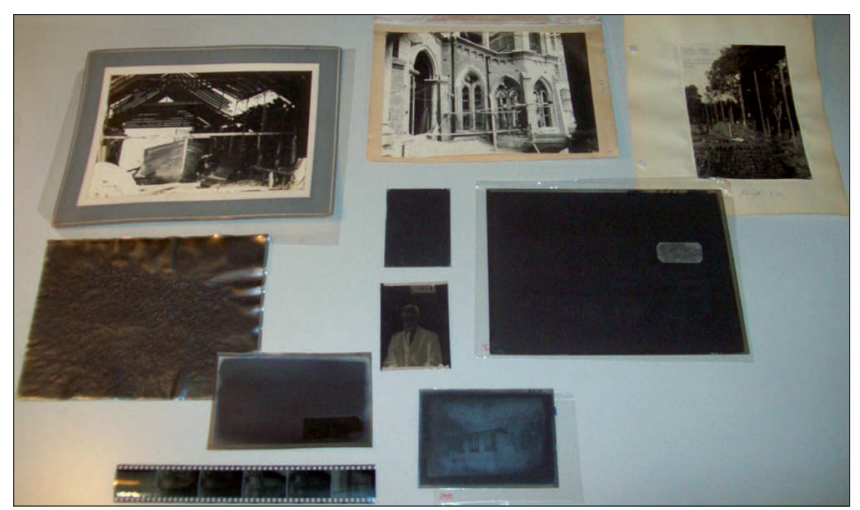

Soportes. Toma fotográfica de diversos soportes. CeDIAP.

mina, papel a la gelatina, gelatina sobre vidrio, nitratos, acetatos.

- Estado de los soportes. Se presentan deterioros como cambio de color, craquelado, desprendimiento y/o perdida parcial de emulsión, emulsión brillante, espejamiento, 


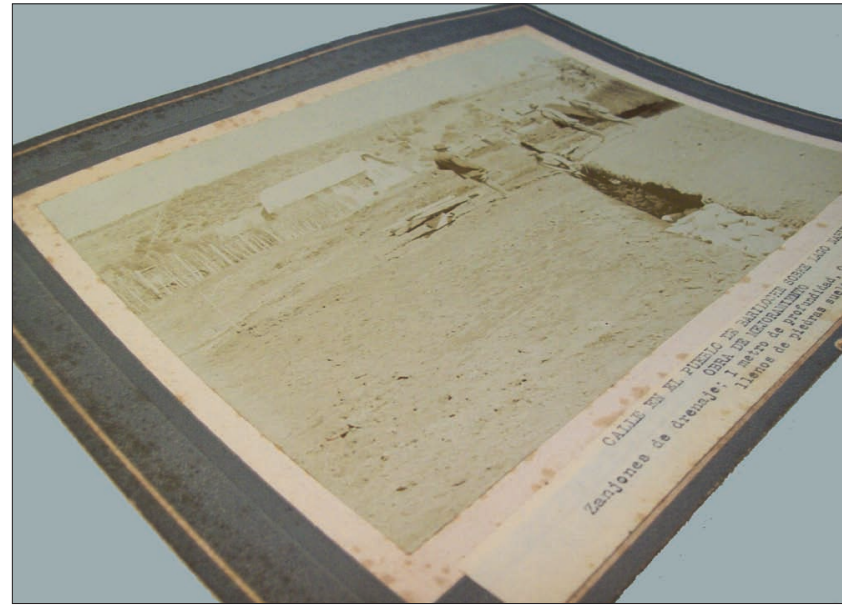

Técnica. Toma fotográfica de una albúmina de 1914. CeDIAP.

huellas digitales, imagen lechosa, óxido de reducción, retocado, partículas indesprendibles y roturas.

- Usos de la información. Los más frecuentes están vinculados con la investigación, la intervención y el mantenimiento de edificios. Las fotografías permiten analizar las resoluciones formales, la evolución de los sistemas constructivos y tecnológicos empleados por el Estado, observar los cambios sociales, culturales, políticos y económicos, vinculándolos con la vida político-institucional del país. Usadas como documentos de estudio y análisis, permiten conocer la evolución de las intervenciones, comprender la obra y actuar en consecuencia, economizar recursos y proponer intervenciones responsables.

- Valoración documental. Los fotógrafos de esta colección son "ocultos artistas detrás de la cámara". Se trató de empleados públicos que trabajaron en el laboratorio del que fuera Ministerio de Obras Públicas, sin registrar ni identificar sus nombres en los libros de inventario. A las consignas en relación a cuestiones técnico-arquitectónicas, ellos sumaron el manejo de recursos propios del lenguaje fotográfico, impregnando de valor artístico muchos de los documentos. Tipo de encuadre, iluminación, enfoque, inclusión de personajes y su circunstancia trascienden lo puro y exclusivamente documental, y resultan en imágenes de gran valor estético.

Gran parte del material, cuyo soporte y técnica está en desuso, da testimonio de los recursos que la fotografía ofrecía para documentar. Su valor deriva de su antigüedad y testimonia los avances tecnológicos de una época.

\section{Gestión integral del fondo}

Debido a la Reforma del Estado de fines de 1980, muchos de los edificios que albergaban archivos gubernamentales fueron desocupados. Esto se llevó a cabo sin contemplar la protección de colecciones durante su traslado y relocalización. El archivo de fotografías de la obra pública se encontraba entonces en riesgo y la primera acción que se realizó fue el rescate y traslado de originales sumamente frágiles, álbumes con copias fotográficas y libros de inventario.

Luego se evaluó el tipo y volumen del material, se acondicionó el espacio físico para la guarda con sistemas de tratamiento de aire y prevención contra incendio, y se ad- quirieron estanterías y contenedores para conservación de material fotográfico. Hoy los parámetros de temperatura y humedad siguen estándares internacionales (ICA, 2000; $A A E, 2004)$ para compatibilizar los requerimientos de papel y negativos, pues la sala también alberga la colección de planos.

A esto siguió la aplicación de medidas de estabilizado según recomendaciones para tratamientos de conservación (Iccrom, 1996; INTI).

Simultáneamente se identificó, inventarió y sistematizó el material, y se cargaron registros y planillas de inventario en base de datos.

También comenzó la captura digital, primero de las copias y años después de los negativos fotográficos con la adquisición de un scanner apto para traslúcidos. Los estándares originales se fueron adecuando en base a parámetros recomendados (Cía; Fuentes, 2000; Ministerio de Cultura de España, 2002; Cornell University, 2003; Comisión Europea, 2006; Fadgi, 2009; Boro, 2010).

El proceso de digitalización, documentado en manuales de procedimientos que fijan pautas respecto de prioridades, criterios de selección y casos en que el soporte no admite ser manipulado, contempla la siguiente secuencia de tareas (Castillo, 2008):

- Selección de documentos.

- Verificación, evaluación y preparación del soporte.

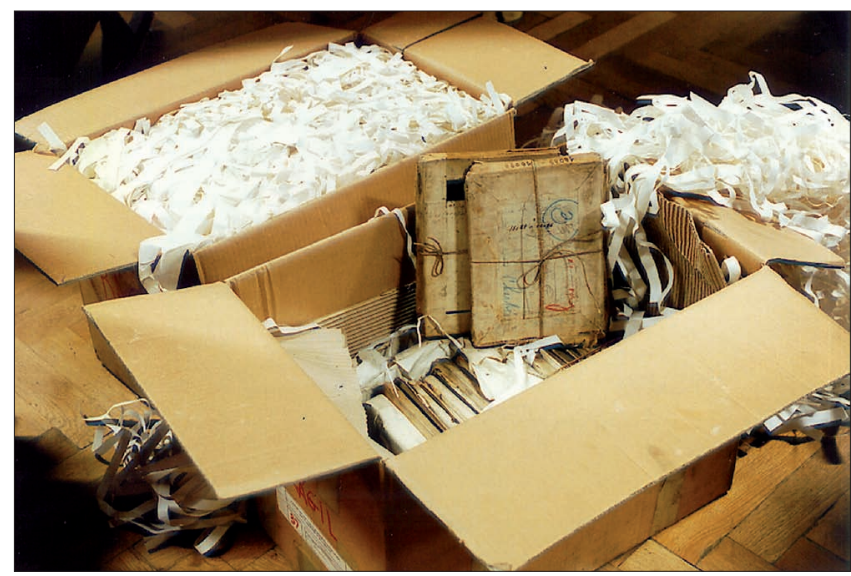

Rescate. Negativos de vidrio en cajas originales durante el rescate. CeDIAP

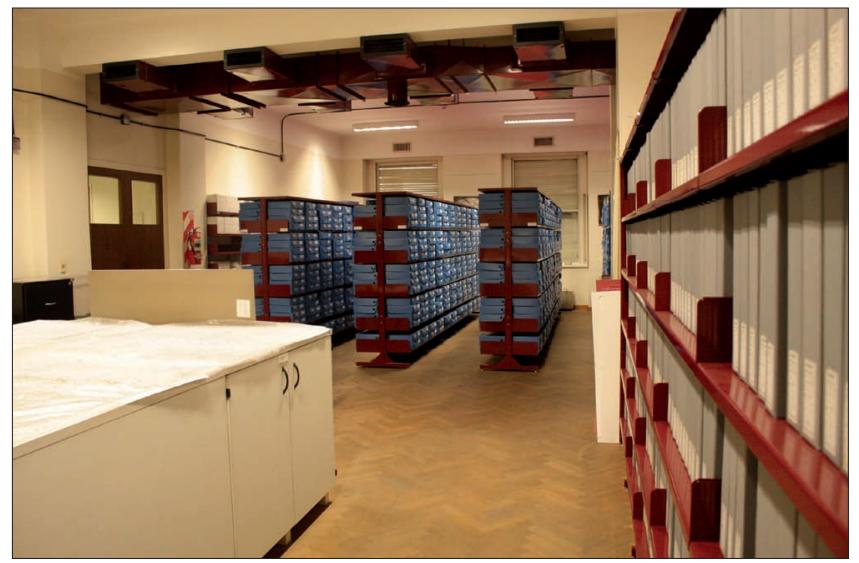

Guarda. Vista general del archivo acondicionado especialmente para el guardado de planos y fotografías. CeDIAP 


\begin{tabular}{|l|c|c|c|}
\hline \multicolumn{1}{|c|}{ Tipo de copia } & $\begin{array}{c}\text { Profundidad } \\
\text { de bits }\end{array}$ & $\begin{array}{c}\text { Resolución } \\
\text { (varía en } \\
\text { función del } \\
\text { tamaño del } \\
\text { original) }\end{array}$ & Formato \\
\hline $\begin{array}{l}\text { Máster de preservación } \\
\text { (original digital sin } \\
\text { edición) }\end{array}$ & $\begin{array}{c}16 \text { bits } \\
\text { (escala de } \\
\text { grises) ó } \\
32 \text { bits (modo } \\
\text { RGB) }\end{array}$ & 300 a 2000 dpi & tiff \\
\hline $\begin{array}{l}\text { Copia de consulta } \\
\text { (para acceso rápido) }\end{array}$ & 8 a 24 bits & 150 a 1000 dpi & jpg \\
\hline $\begin{array}{l}\text { Copia servicio digital } \\
\text { (lleva marca de agua) }\end{array}$ & 8 a 24 bits & 96 dpi & jpg \\
\hline
\end{tabular}

Cuadro 1. Tipos de copias digitales y parámetros de referencia

- Generación del máster digital.

- Producción de copias de trabajo.

- Control de calidad.

- Registro, almacenamiento y resguardo.

Una única captura digital genera la copia master de preservación y a partir de ella se producen diversas copias según su aplicación, de acuerdo con el cuadro 1:

Los tres tipos de archivos digitales requieren, para su edición, guarda y acceso, diversos recursos informáticos. Dada la disponibilidad en el organismo, se utilizan:

- discos ópticos locales para captura y procesamiento

- cintas magnéticas para almacenamiento de máster para preservación

- terminales en red con servidores remotos para consulta en sala de copias de trabajo y servicio de reprografía.

La digitalización implicó lidiar con migración de formatos, incompatibilidad de hardware y software e insuficiencia del almacén digital

Al planificar la digitalización de una colección o fondo, especialmente si se trata de un archivo voluminoso como este y los recursos no están en la proporción esperable, la innovación informática y de comunicación suele ocasionar dificultades. A lo largo de quince años debimos sortear inconvenientes para alcanzar metas propuestas de calidad. Mayor velocidad de procesos y calidad superior de imágenes digitales determinaron:

- Migración de formatos. La primera captura digital se realizó en formato jpg; años después, hubo que repetir la digitalización para generar másteres tiff. Con la implementación de la base de datos actual, en 2010 las copias de consulta debieron migrarse de tiff a jpg para permitir que el visualizador con el que opera el sistema reconozca el formato y el registro pueda vincularse con su imagen.

- Ordenador, software y equipos de captura. Cuando no se renovaron simultáneamente, surgieron problemas de incompatibilidad.

- Almacén digital. Como los nuevos recursos informáticos permitieron incrementar la producción y calidad de do-

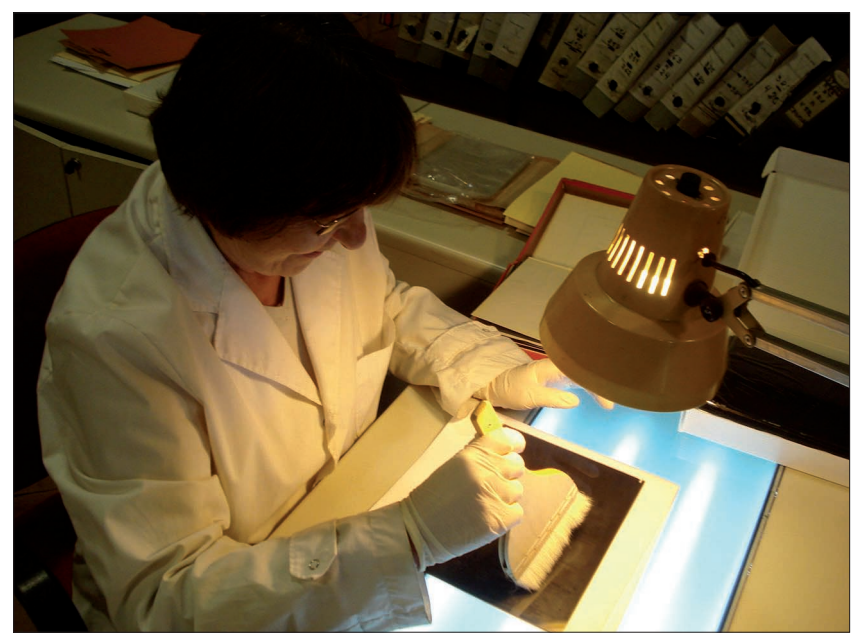

Conservación. Conservación preventiva aplicada a negativo de vidrio 18x24. CeDIAP

cumentos digitales, se tornaron más complejas las tareas de resguardo y control de calidad de los archivos digitales máster para preservación, y se requirió mayor espacio de almacenamiento. Para dimensionar adecuadamente los almacenes digitales, fue necesario planificar y cuantificar la producción, previendo su volumen futuro.

Concluyendo, antes del diseño del proyecto de digitalización se evaluaron:

- Material (tipo, volumen, soportes, estado de conservación, temática)

- Destinatarios (reales y potenciales)

- Recursos humanos y tecnológicos

- Servicios a brindar y políticas de acceso

Estas evaluaciones permitieron decidir que la captura digital se realizaría en la institución, en lugar de tercerizar el proceso u optar por un sistema mixto. Para la implementación del proyecto se establecieron políticas y pautas atendiendo:

- Criterios de selección del material: según demanda de usuarios, estado del soporte, el volumen y contenido de la colección, etc.

- Recursos humanos: incorporación de profesionales, técnicos y especialistas y capacitación de agentes del organismo.

- Espacio físico y equipamiento: organización del ámbito de trabajo y equipamiento específico.

- Selección y adquisición de recursos informáticos: cotejando oferta de mercado, resultados deseados y disponibilidad económica.

- Indicadores de producción y plazos de ejecución.

- Elaboración de manuales y normas, control de calidad y servicios (Castillo, 2008).

Junto con el Área de Redes y Sistemas del CDI, el CeDIAP concluyó en 2010 una nueva base de datos que cuenta con aproximadamente 180.000 registros y se encuentra en proceso de ajuste. Reemplaza la diseñada en los comienzos, ya inoperable de tan obsoleta y frágil.

El desarrollo incluye migración de registros, introducción de nuevos campos y normalización de los puntos de acceso utilizando entre otras herramientas, vocabularios controlados específicos (Vitruvio, 2004). 


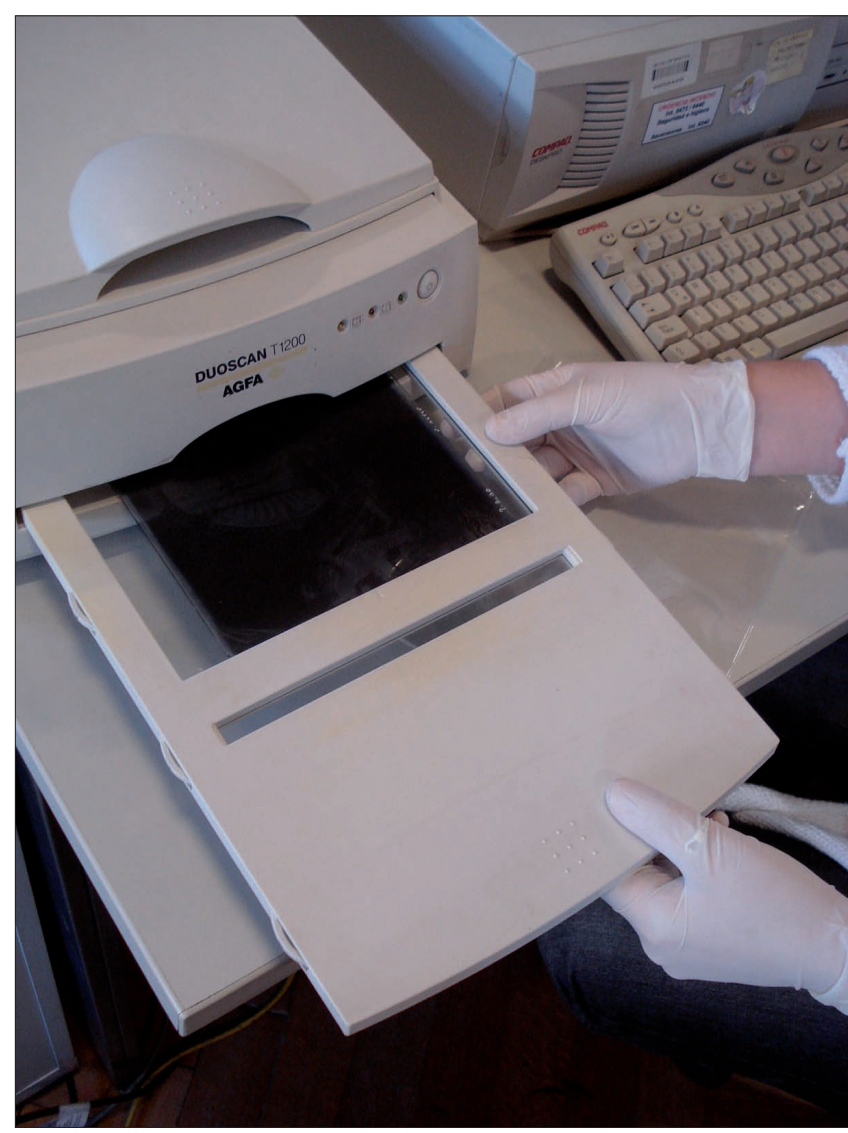

Digitalización. Proceso de digitalización de un negativo fotográfico en soporte vidrio. CeDIAP

Otorga mayor accesibilidad a la información, permite la planificación de tareas y responde a la necesidad de superar las dificultades de la anterior. Al capitalizar la experiencia y errores, al momento de tomar decisiones optamos por:

- Emplear software no propietario.

- Utilizar normas de descripción y catalogación estandarizadas [ISAD(G), 2000].

- Realizar un análisis previo de las prestaciones que se esperan del producto.

- Implementar progresivas reuniones entre "cliente" y "desarrolladores".

La nueva bdd responde a normas de descripción multinivel, facilita la planificación y el seguimiento de procesos, y permite la visualización de imágenes

La migración fue realizada de Access a Winisis y de Winisis a $A b c d$, abriéndose la posibilidad de su migración a mejores plataformas en el futuro.

La demanda de los usuarios es cada vez mayor. Dependiendo del uso, las reproducciones digitales se entregan en diversos formatos y resoluciones, e incluso se envían a distancia.

Si bien el servicio es gratuito (por Decreto 1172/2003 que rige sobre el acceso a la información pública), la duplicación para productos culturales (libros, investigaciones, exposiciones, etc.) requiere del compromiso del usuario a citar las

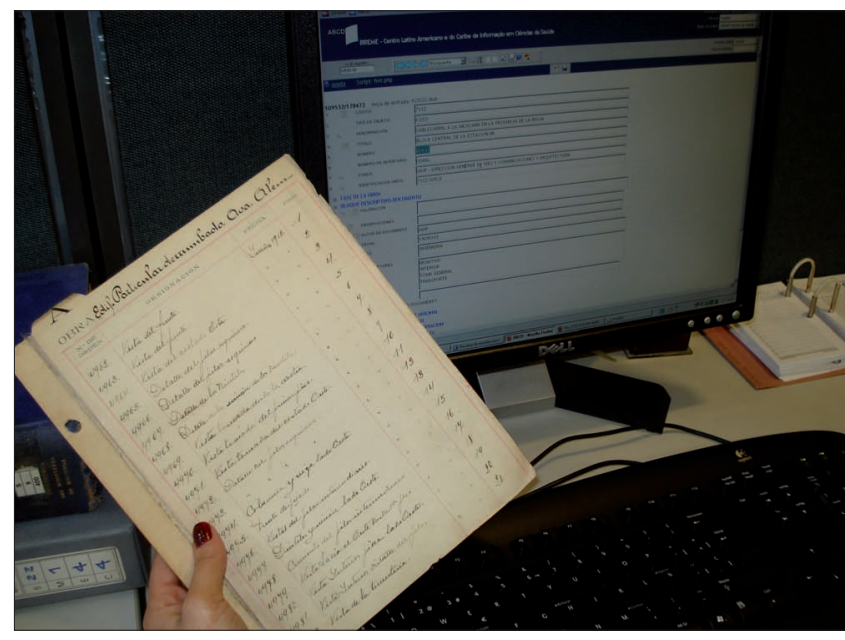

Sistematización. Registro original en proceso de sistematización en base de datos. CeDIAP

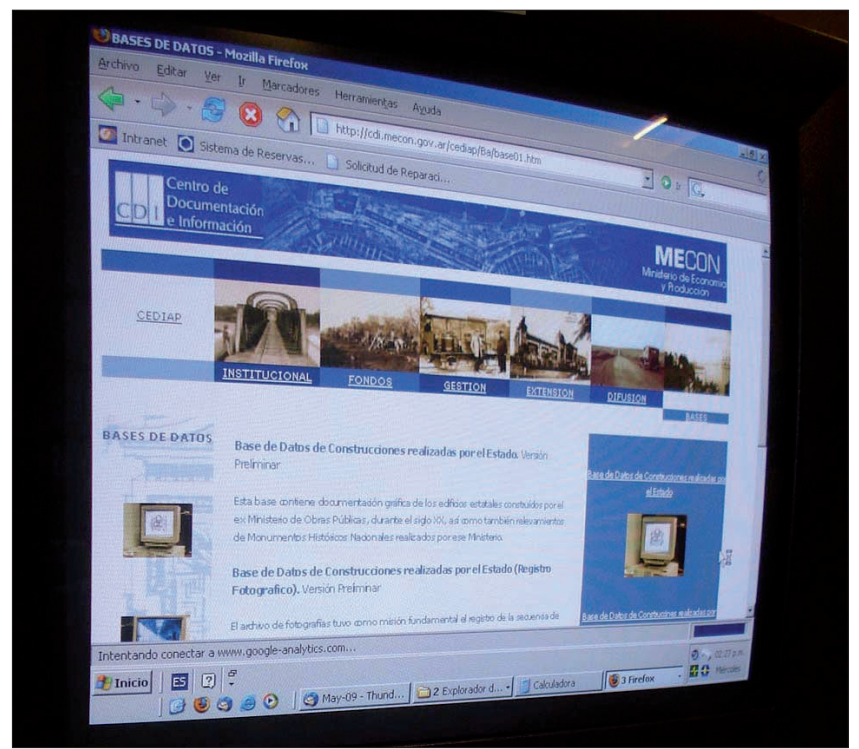

Acceso. Sitio web del CeDIAP

fuentes y brindar una contraprestación (donación de material de archivo, ejemplares de la publicación, etc.).

En los comienzos, la difusión revirtió la imagen del "depósito de expedientes" al promocionarse el valor del archivo original y la apertura al público

Desde entonces, el CeDIAP participa de muestras, coopera en la elaboración de presentaciones, aporta documentación para publicaciones, y además organiza exposiciones en el organismo, contribuyendo al tejido de la memoria colectiva.

\section{Relevancia de la gestión integrada}

La gestión de la colección de fotografías se complementa, enriquece y contextualiza con la gestión de información bibliográfica de otras áreas del $C D I$, obteniendo una visión integral de la historia edilicia. Esta gestión transversal de la información permitió, en el $70^{\circ}$ aniversario del Palacio de Hacienda, organizar una muestra durante la Noche de los Museos 2009. Más de 1.800 personas pudieron conocer la historia del organismo mediante exposiciones, vídeos, visitas guiadas y música. 


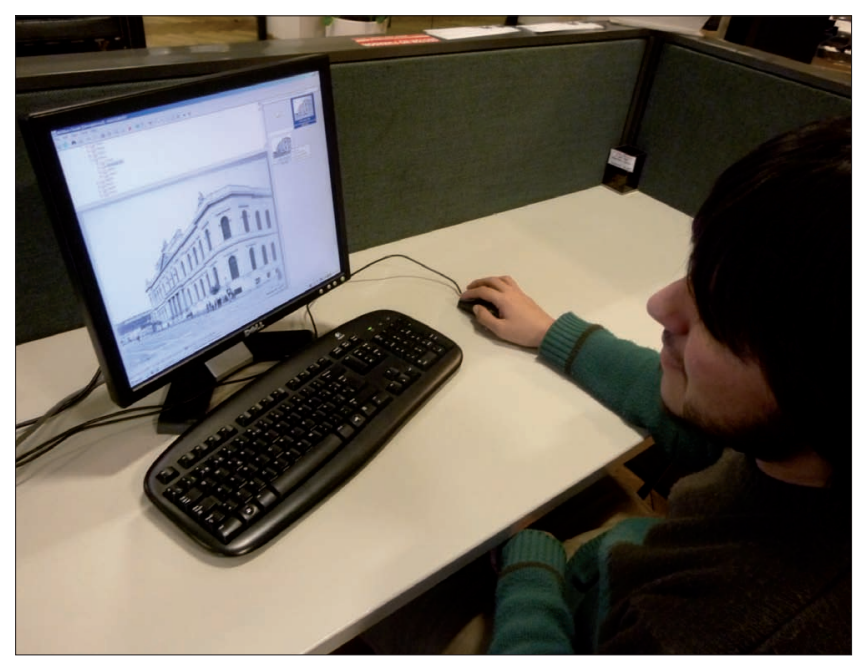

Acceso. Terminal de consulta en sala. CeDIAP

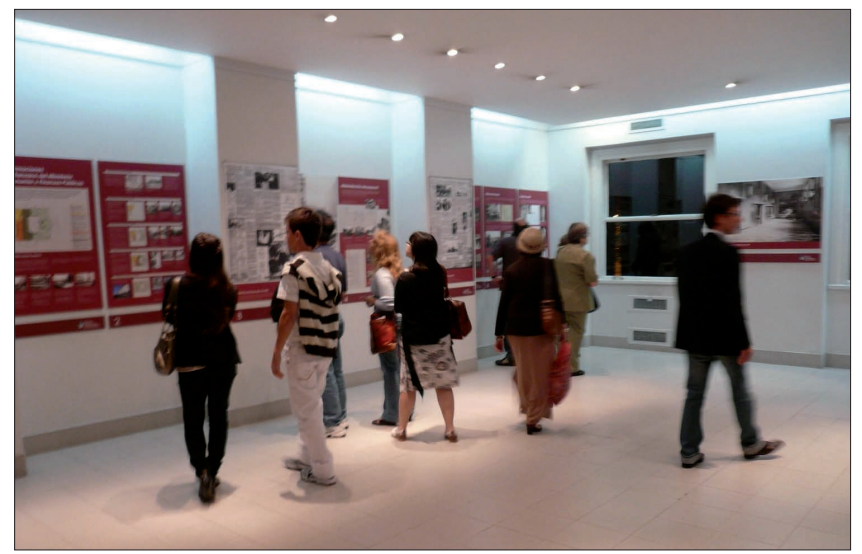

Difusión. Exposición Bicentenario - Aniversario Mecon 2a parte. Noche de los Museos organizada por el CDI el 14-11-2009

Para el $C D I$ fue un hito exitoso que produjo cambios en la forma gestionar objetivos. Se conformó una comunidad de práctica interáreas y se adquirieron conocimientos y herramientas para la investigación, lo cual agregó valor a los fondos documentales. A través de la capacitación en manejo de bases de datos y la sensibilización sobre las características de la información, se logró incrementar el nivel de compromiso y ampliar las competencias de los participantes en el proyecto. Normativa, planos y fotos, propagandas, construcción y presupuesto, datos biográficos, datos de construcción edilicia, libros aniversario: todos fueron tratados con métodos específicos de gestión de información. Participaron otras dependencias y archivos del Ministerio, y los datos se sistematizaron desde distintos ángulos permitiendo elaborar distintos productos de difusión.

La gestión integral del fondo contempla aspectos físicos y de contenido, recursos humanos y tecnológicos, políticas de acceso, servicios y productos de difusión, evaluando demandas reales y potenciales

La creación de contenidos para difusión es una meta que el $C D /$ se ha propuesto como modo de comunicar su trabajo en memoria institucional y la consolidación de la información bibliográfica y documental. Con la sistematización de los procesos desarrollados en actividades transversales, y del uso de la multicanalidad de servicio que ofrecen distintas herramientas web, el CDI gestiona el conocimiento organizacional, sistematizando las actividades transversales y difundiendo las experiencias recogidas hacia otras redes.

La gestión de la memoria institucional y el patrimonio documental permite reconstruir la historia institucional y contribuir a la reconstrucción de la historia de la Nación. Dando respuesta a preguntas sobre la institución y quienes impulsaron su desenvolvimiento, se da testimonio de lo realizado a las generaciones actuales y futuras, y se promueve la producción y circulación de objetos culturales.

\section{Bibliografía}

Architectural Archives in Europe. Guidelines to managing architectural records. Europe: 2004.

Boro, Fernando. Fundamentos para la gestión de largo plazo de colecciones digitales. Buenos Aires: Facultad de Filosofía y Letras (UBA), junio 2010.

Cardinal, Louis; Daniels, Maygene; Peyceré, David; Souchon, Cécile; Van Nieuwenhuysen, Andrée. A guide to the archival care of architectural records, 19th-20th centuries. Paris: International Council on Archives, 2000.

Castillo, Susana. Lidiando con fotos y planos: el ciclo de vida de un proyecto. Buenos Aires: CeDIAP, 2008.

Cía-Zabaleta, Jesús; Fuentes, Ángel. "Notas sobre la conservación digital de colecciones fotográficas antiguas". Lligall, 2000, n. 16, pp. 243-253. Associació d'Arxivers de Catalunya.

Comisión Europea. Recomendación de la Comisión de 24 de agosto de 2006 sobre la digitalización y la accesibilidad en línea del material cultural y la conservación digital. Bruselas: 31 agosto 2006.

Cornell University. Tutorial de digitalización de imágenes: llevando la teoría a la práctica. New York: 2003.

Federal Agencies Digitization Initiative (Fadgi) - Still Image Working Group.

Technical guidelines for digitzing cultural heritage materials: creation of raster image master files, 2009.

Instituto Nacional de Tecnología Industrial. Boletín sobre conservación y restauración (varios números). Buenos Aires: INTI.

Instituto Argentino de Normalización y Certificación (IRAM). Norma argentina IRAM-ISO/IEC 27001: tecnología de la información, sistemas de gestión de la seguridad de la información (SGSI), requisitos. Buenos Aires: 2007.

López-Castro, Guillermo; Medus, Norma; Prado, Stella-Maris. "La memoria en imágenes, una experiencia de digitalización: archivo histórico provincial Fernando E. Aráoz". En: Congreso de historia de la fotografía en la Argentina, Buenos Aires: octubre 2003, pp. 141-143.

Ministerio de Cultura [España]. Directrices para proyectos de digitalización de colecciones y fondos de dominio público, 
en particular para aquellos custodiados en bibliotecas y archivos. Madrid: marzo 2002.

De-Navascués-Benlloch, Asunción; Carnicer-Arribas, MaríaDolores; Desantes-Fernández, Blanca; Moreno-López, Guadalupe. ISAD (G): norma internacional general de descripción archivística. Madrid: Consejo Internacional de Archivos, 2000.

Northeast Document Conservation Center. Storage and handling. Andover, Massachusetts: Nedcc.
Poder Ejecutivo Nacional [Argentina]. "Decreto 1172/2003: acceso a la información pública". En: Boletín Oficial, Buenos Aires: 4/12/03, n. 30291, p. 1.

Proyecto Calimera. Pautas de buena práctica. ¿Lisboa?: Comisión Europea, ¿2006?

Red de Bibliotecas de Arquitectura, Arte, Diseño y Urbanismo (Vitruvio). Vocabulario controlado de arquitectura, arte, diseño y urbanismo. Buenos Aires: Grebyd, 2004.

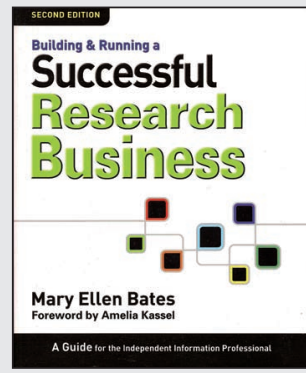

\section{Building \& running a successful research business: a guide for the in-} dependent information professional Mary-Ellen Bates

Actualización de la primera edición de 2003 del conocido manual de Mary-Ellen Bates, Building \& running a successful research business: a guide for the independent information professional (Establecimiento y funcionamiento de una consultoría de información de éxito. Una guía para el profesional de la información autónomo), se trata de un completo manual para el profesional de la información que quiere establecerse por su cuenta y convertirse en un "information broker". Bates, una conocida profesional de la información, da pautas para cada paso del proceso, desde el “¿Está usted de acuerdo con estas especificaciones?" hasta cerrar la venta de un trabajo o proyecto: gestión de clientes, promoción del negocio en la web, y aprovechamiento de las fuentes de información más allá de la Web.

El libro tiene 38 capítulos organizados en 4 secciones: "Cómo empezar", "El día a día", "Marketing" e "Búsqueda de información".

La segunda edición, totalmente actualizada, se ha ampliado un 40\%. Cuenta con nuevos capítulos sobre posicionamiento del negocio, marketing a través de los medios de comunicación social, creación de una presencia web efectiva, planificación estratégica a cinco años, y cómo redactar un plan de marketing.

El libro incluye una introducción del autor, opiniones de otrosprofesionales liberales, y tres anexos proporcionan información sobre la Association of Independent Information Professionals, listas de sitios web recomendados, e información biográfica y de contacto de las personas citadas en el libro.

Bates, Mary Ellen. Building \& running a successful research business: a guide for the independent information professional, $2^{\text {nd }}$ ed., 2010, 528 pp. ISBN: 9780910965859

Precio: \$34,95, Information Today, Inc. (ITI) custserv@infotoday.com http://www.infotoday.com

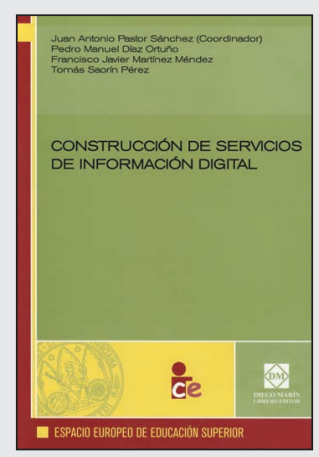

\section{Construcción de servicios de información digital Juan-Antonio Pastor-Sáchez (coord.), Pedro-Manuel Díaz-Ortuño, Francisco-Javier Martínez-Méndez, Tomás Saorín-Pérez}

La obra ofrece una serie de contenidos teóricos de carácter básico, en el ámbito de la formación en el diseño y desarrollo de servicios y sistemas de información digital. Los capítulos 1 y 2 tratan sobre la realidad actual de los productos y servicios de información digital y la infraestructura conceptual que suponen los sistemas de información. En el capítulo 3 ofrece una visión histórica de internet, del surgimiento, evolución, arquitectura y principales aplicaciones (web y correo electrónico). El capítulo 4 muestra las diferentes soluciones existentes para realizar servicios y productos en la Web. El capítulo 5 incluye una aproximación a los esquemas de organización y acceso a la información basados en los hipermedia y en el diseño integral web, como una combinación de tres de disciplinas que abordan el desarrollo completo de cualquier servicio basado en la web: accesibilidad, usabilidad y arquitectura de la información. Los sistemas de gestión de contenidos (CMS) se abordan en el capítulo 6. La obra finaliza con un capítulo dedicado a la web semántica.

Pastor-Sánchez, Juan-Antonio (coord.); Díaz-Ortuño, Pedro-Manuel; Martínez-Méndez, Francisco-Javier; Saorín-Pérez, Tomás. Construcción de servicios de información digital, 2010, 239 pp. ISBN: 9788484257844 